\title{
Crystallization of jarosite in the presence of amino acids
}

\author{
Harrison Crabbe, Natalya Fernandez, Franca Jones* \\ Curtin University, Department of Chemistry, GPO Box U1987, Perth WA Australia 6845. Fax: $61892664699 ;$ Tel: 618 9266 7677; \\ E-mail: F.Jones@curtin.edu.au
}

\section{Abstract}

Jarosite was formed in the presence of five amino acids at two pHs, namely 1.75 and 2.9, to determine what impact amino acids have on its formation. It was found that at the lower $\mathrm{pH}$ glycine was the most potent in terms of morphological and yield impacts. XRD analysis showed that incorporation of the amino acid occurs at this low $\mathrm{pH}$ for glycine and proline. Dynamic light scattering studies showed that glycine impacts significantly on the jarosite nucleation rate while proline and alanine do not. At the higher $\mathrm{pH}$ all of the amino acids had much less impact on morphology or yield. At $\mathrm{pH} 3$ the solids were found to be a 3-phase system consisting of goethite, schwertmannite and jarosite. In this case, alanine appeared to stabilize the presence of schwertmannite more than the other amino acids.

Keywords: A1. Impurities, A1. Nulceation, A2. Growth from solution, B1. Minerals, B1. Potassium compounds

\section{Introduction}

Jarosite, $\left[\mathrm{KFe}_{3}\left(\mathrm{SO}_{4}\right)_{2}(\mathrm{OH})_{6}\right]$, is a mixed iron sulphate mineral commonly found in environments such as acid sulphate soils [1], acid mine wastes [2], saline lakes [3] and hypogene systems [4]. It is also produced in some hydrometallurgical operations (such as zinc processing) to remove unwanted iron and improve metal concentrates [5, 6]. Given that jarosite only forms when water is present, the finding of jarosite on Mars in 2004 confirmed that the 'Red planet' had water at some point in its history [7]. The formation of jarosite is, therefore, of wide interest in many fields. 
In terrestrial systems, microbes are always present, and this is especially true of acid mine drainage systems where oxidizing bacteria often control the iron and sulphur levels of the system (through organisms such as thiobacillus ferrooxidans [4]). The relationship between jarosite and microbes is, however, not fully understood although some research has been conducted in this area $[5,6,8-10]$. In the case of acid mine drainage, jarosite formation could be extremely beneficial by locking away toxic metals often released by the high acidity, however, this depends on the stability of the jarosite in this environment. ${ }^{11}$ Thus, understanding the formation and stability of jarosite in acid environments is of fundamental interest and has many real world applications.

Generally, it is well understood that thiobacillus ferriooxidans-type microbes will dissolve pyrite and can thereby form jarosite solids [12, 13]. For the most part, literature is also agreed that below pH 3 jarosite will form $[9,14]$ while above $\mathrm{pH} 3$ and below $\mathrm{pH} 5$ schwertmannite is the product formed. However, this is temperature dependant $[10,14]$. From an acid mine drainage point of view we find that the bacteria that grow well in the conditions required for jarosite formation must be acidophiles $(\mathrm{pH}$ must be below 3). The $\mathrm{pH}$ is however, also linked to the rate of iron (II) which is oxidised to iron (III) [15] in natural systems and to the extent of sulphur-bearing minerals. If jarosites are to be used as repositories of waste materials (in particular, heavy metals) in the remediation of acid mine drainage soils [11], not only their stability in different environments and possible dissolution behaviour must be determined (as already acknowledged) but also the impact microbes have on this process is also vital. Some of this work is already being conducted [16-18] showing the dissolution of different jarosites containing lead or arsenic within the structure but these are in the absence of microbial action. The stability of solids in various environments is, however, also linked to their structure, so one could ask whether the presence of microbes induces 
the formation of jarosites with different structure and therefore properties. Again, early work is showing that jarosites formed in the presence of microbes may have different features [19] suggesting that there are differences between biogenic jarosite and synthetic jarosites $[14,20]$. There is also the suggestion that particular microbes promote the presence of different phases [8], however, as stated above $\mathrm{pH}$ and temperature are also significant contributors to this. Finally, it should be stressed that microbial action need not form jarosite directly but can be a consequence of the conditions they create; for example, the work of Tazaki et al. [21], show that during the corrosion of a sewer pipe (the microbes present are inferred to have caused the corrosion), the acidic conditions present and maintained by the microbes in the pipe result in jarosite and gypsum formation.

As high-grade ores diminish, cost effective means of treating low-grade ores must be developed [22]. One such possible method is heap leaching where acid is dripped onto a low-grade ore heap and with the aid of microbes, the desired metals are released, dissolved and thereafter extracted. This process also leads to acid mine drainage. Thus, understanding the interaction between microbe, $\mathrm{pH}$ and solids formed is of vital importance for future mining practices.

As a precursor to understanding the impact that microbes (and live organisms in general) have on jarosite formation, we have looked at amino acids. There is very little literature on the effect of amino acids [23], though as discussed above there is some with regard to microbial impacts [5, 6, 8-10]. From the work of Kotler [23, 24], it was hypothesized that glycine might incorporate into the structure, however this was inferred from infrared evidence, which does not actually conclusively give information on incorporation. This is because movements in peak positions can be due to adsorption effects and may not relate to incorporation at all. Even if such small molecules are not 
incorporated into the jarosite mineral structure, it is probable that they will interact with growing crystallites to modify their growth rate, morphology and particle size. This manuscript, therefore, investigates the formation of jarosite in the presence of 5 amino acids and investigated parameters such as i) yield ii) morphology, iii) the impact of $\mathrm{pH}$ and iv) the possibility of incorporation.

\section{Materials and Methods}

\section{$2.1 \quad$ Materials}

Ferric sulphate $\mathrm{Fe}_{2}\left(\mathrm{SO}_{4}\right)_{3} \cdot \mathrm{xH}_{2} \mathrm{O}$ was obtained from Chem Supply and potassium nitrate was AR grade from Ajax Chemicals. To alter $\mathrm{pH}$, concentrated sulphuric acid $\left(\mathrm{H}_{2} \mathrm{SO}_{4}\right)>95 \%$ from Ajax Chemicals and potassium hydroxide $(\mathrm{KOH})$, AR grade from BDH was used. The amino acids; L-cysteine, D, L-alanine, D, L-aspartic acid, Lproline, D, L-glycine were AR grade from Sigma Aldrich.

\subsection{Jarosite formation and determination of yield}

Potassium jarosite was prepared according to the method of Dutrizac [4, 25]. This involves dissolving $\mathrm{Fe}_{2}\left(\mathrm{SO}_{4}\right)_{3} \cdot \mathrm{xH}_{2} \mathrm{O}(6.4 \mathrm{~g})$ and $\mathrm{KNO}_{3}(24 \mathrm{~g})$ into $800 \mathrm{~g}$ de-ionised water to which $0.8 \mathrm{~mL}$ concentrated $\mathrm{H}_{2} \mathrm{SO}_{4}$ is added to the solution in a clean, glass bottle. The bottle is capped and the resulting clear solution is then heated to $90{ }^{\circ} \mathrm{C}$ for 3 or 24 hours. The $\mathrm{pH}$ measured for more than 3 control samples was $1.75 \pm 0.05$ and so this was one of the pHs chosen to investigate. A higher $\mathrm{pH}$ of 2.9 was also chosen to determine what impact $\mathrm{pH}$ had on the system. After the allocated time; any solids formed are collected by filtering, washing with de-ionised water three times and drying in a desiccator. The solids are then weighed to determine the yield of solid formed. On some occasions, smaller $200 \mathrm{~mL}$ batches were prepared to collect solids at 3 hours to determine the solid phase present only. 
When amino acid is present it is added as a solid prior to the addition of water and dissolved along with the other solids. The addition of amino acids normally raises the $\mathrm{pH}$ of the system and so the $\mathrm{pH}$ is adjusted (using conc $\mathrm{H}_{2} \mathrm{SO}_{4}$ or $\mathrm{KOH}$ ) after dissolution of all solids to the same $\mathrm{pH}$ as the control system or the desired $\mathrm{pH}$.

\subsection{Characterisation of solids}

\subsubsection{Infrared}

Infrared is a well-known method to characterize mineral forms as the technique is phase specific. The solids for Fourier transform infrared (FTIR) were placed onto a diamond ATR accessory of a Nicolet IS50 FTIR Spectrometer. A background spectrum was collected before each new scan. Data were collected from 400 to $4000 \mathrm{~cm}^{-1}$ with a spectral resolution of $4 \mathrm{~cm}^{-1}$ in transmittance mode. All spectra were uncorrected since the spectra were being used for comparison purposes only.

In Figure 1 below, the control jarosite infrared is shown. The peaks compare well with literature [26] where the sulphate bands are found between 940 and $1300 \mathrm{~cm}^{-1}$ and the water bend and stretch bands can be found at 1600 and $\sim 3350 \mathrm{~cm}^{-1}$ respectively. The bands between $1900-2400 \mathrm{~cm}^{-1}$ are due to the diamond ATR and are not from the solids. 


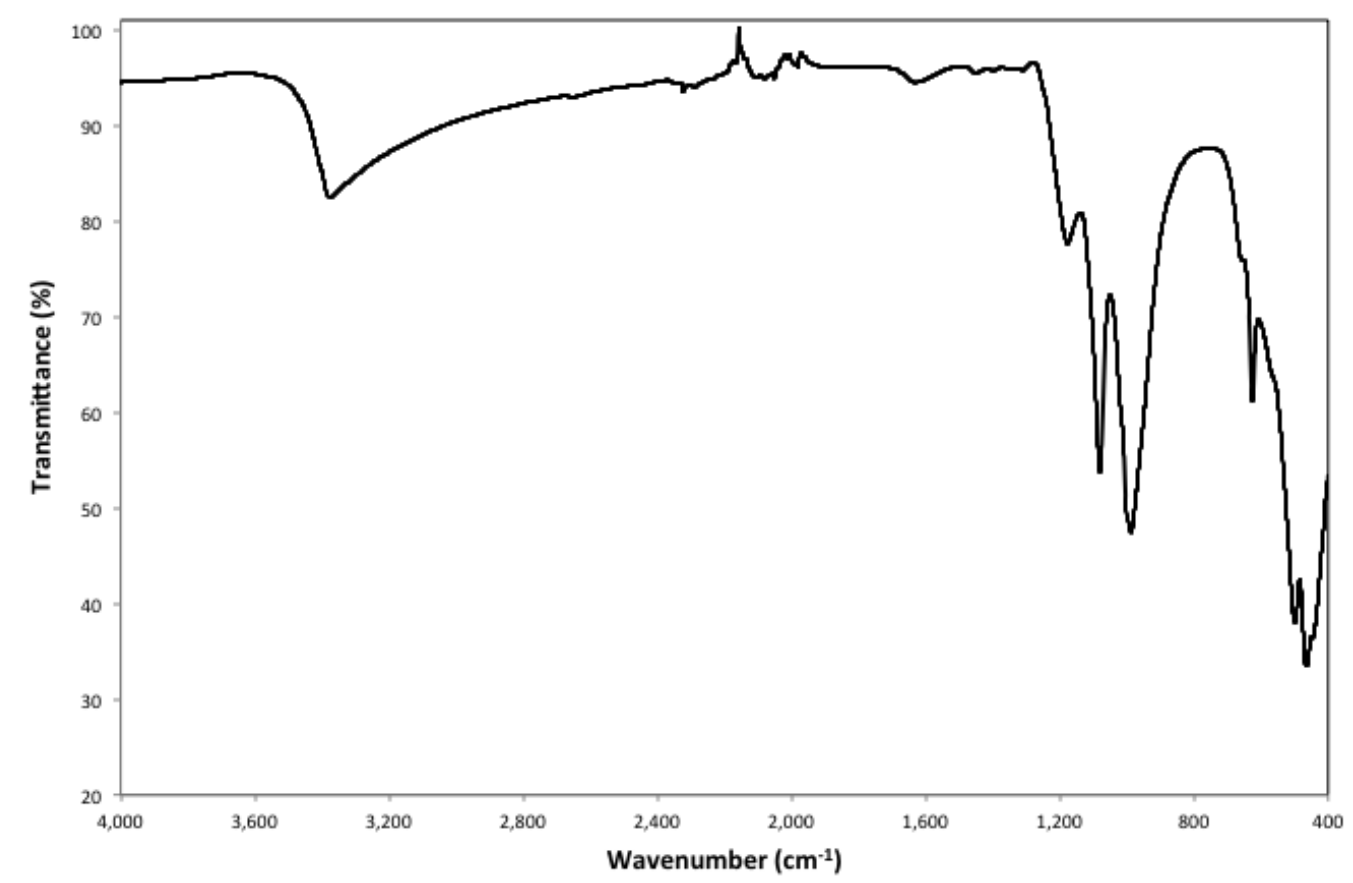

Figure 1. FTIR spectrum of control jarosite solids

\subsubsection{Scanning Electron Microscopy (SEM)}

Morphology of the samples was determined using an Evo Zeiss scanning electron microscope (SEM). The washed and dried solids from crystallization experiments were placed on carbon coated SEM stubs and placed in a dessicator to let the stubs dry. They were then sputter-coated with gold prior to viewing on an Evo Zeiss SEM instrument. The images were usually collected at a working distance of $10 \mathrm{~mm}$ and a voltage of $15 \mathrm{kV}$.

\subsubsection{X-ray diffraction (XRD)}

Wide angle, powder XRD was performed on the samples containing sufficient solids to pack the XRD holder of a D8 Advance (Bruker) instrument with a 2theta range of $7-70^{\circ}$, step size 0.001 , divergence slit of $0.3^{\circ}$ while the sample holder was spun at 30 rpm. $\mathrm{Cu} \mathrm{K}_{\alpha}$ radiation was used for these samples. In addition, some samples were repeated with a corundum internal standard $(\sim 10 \%)$ and run at $5-120^{\circ} 2$ theta using Co $\mathrm{K}_{\alpha}$ radiation, step size 0.01 on a D8 Discovery (Bruker) instrument. These XRD 
patterns were used for Rietveld analysis undertaken with TOPAS ${ }^{\circledR}$ software. Finally, for those samples where insufficient solids were present to pack into the regular holders, these samples were dispersed in ethanol and cast onto low background silicon holders and run as per the other samples on the D8 Advance. The XRD pattern of the control sample confirmed the presence of jarosite (Figure 2) and was able to be indexed to the PDF file 00-036-0427.

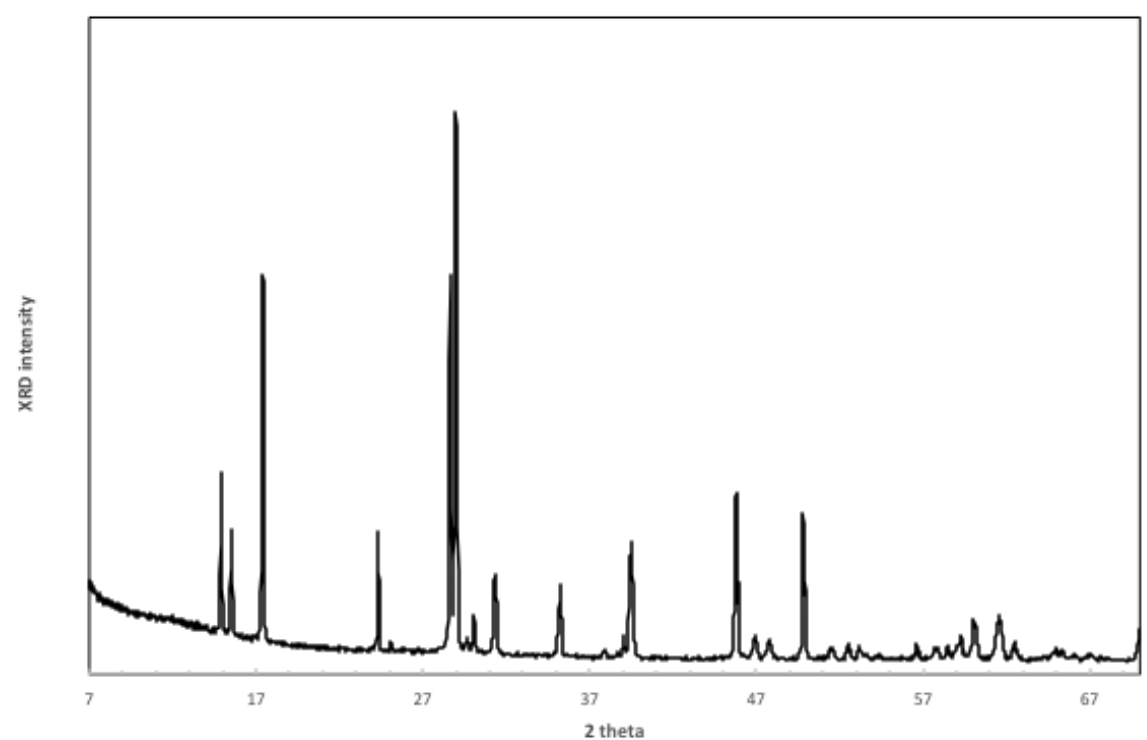

Figure 2. XRD pattern of control jarosite solids

\subsubsection{Dynamic Light Scattering (DLS)}

A Malvern Nanosizer ZS was utilised to measure the DLS behaviour of solutions in the absence and presence of amino acids $(0.14 \mathrm{M})$. This instrument can operate at high temperatures and so the particle sizing and particle counts were obtained at $90{ }^{\circ} \mathrm{C}$ as per the crystallization experiments. The concentrations of iron sulphate, potassium nitrate and sulphuric acid were as per the crystallization experiments except that the $\mathrm{pH}$ of the solutions was adjusted to $\mathrm{pH}=2.1$ for all samples. The DLS gives essentially two pieces of information, the particle counts and the particle size. The particle size will naturally increase over time to its steady state value, while the particle counts will be low until nucleation occurs and then will increase until a steady state is 
reached (in a batch system). The induction time is the time for nucleation to be measured (different techniques will measure different induction times due to the fact the they will have different limits of detection but provided the same instrumentation is used, the induction times are inversely proportional to the nucleation rate), which in this instance is the time required for the counts to increase above background levels. Thus the particle counts were used to determine an effective induction time as this is related to nucleation rates [27].

Control jarosite solids were also placed in a solution containing all but the iron sulphate and heated to $90{ }^{\circ} \mathrm{C}$ for 24 hours, the $\mathrm{pH}$ of the solution being adjusted to $\mathrm{pH}$ $2.0 \pm 0.5$ with and without glycine $(0.28 \mathrm{M})$ present. The solution was filtered through a $0.1 \mu \mathrm{m}$ membrane filter and sent for Fe analysis by inductively coupled plasma - atomic emission spectroscopy (ICP-AES), to assess differences in solubility of the solids when glycine is present.

\subsubsection{Thermal Gravimetric Analysis (TGA)}

TGA analysis was conducted on a TA Instruments SDT 2960 simultaneous DSC-TGA from ambient to $800{ }^{\circ} \mathrm{C}$ at $5{ }^{\circ} \mathrm{C}$ per minute in air at a flow rate of $40 \mathrm{ml} / \mathrm{min}$ using nitrogen gas. Approximately $15 \mathrm{mg}$ of sample was heated in a platinum pan for each measurement. The temperature of the instrument was calibrated against the melting points of indium, zinc, tin, silver and gold. The balance was calibrated over the temperature range with standard alumina weights as provided by the vendor.

\section{Results}

At the very low $\mathrm{pH}$ of 1.75 it was found that very little cysteine or aspartic acid dissolved $(\leq 0.01 \mathrm{M})$. This is most probably due to the fact that at these $\mathrm{pHs}$ these amino acids are neutral or closer to being neutrally charged than the other acids investigated. 
As such, the impact of these two amino acids was found to be negligible and are not further discussed.

\subsection{Morphology}

The particles formed in the absence of amino acids were similar to those of

Sasaki [19]. They contained facets probably consisting of (210) and (001) faces. On addition of the amino acids, the solids formed contain fewer well-defined facets and are much more rounded. In addition, all systems showed significant aggregation.

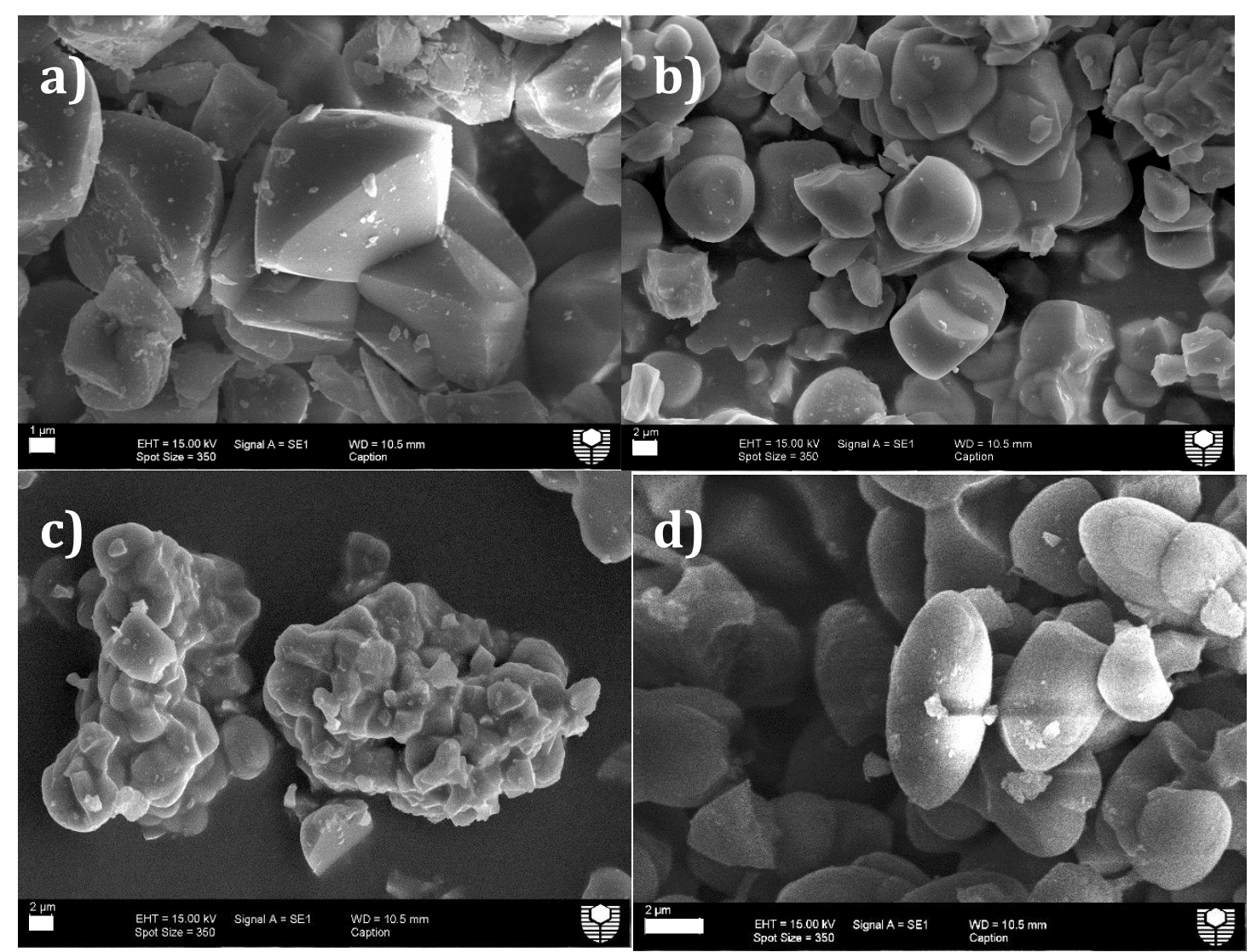

Figure 3. SEM images of jarosite particles formed in the presence of a) no additives (control), and $0.14 \mathrm{M} \mathrm{b}$ ) alanine, c) proline and, d) glycine (all scale bars $2 \mu \mathrm{m}$ except for (a) which is $1 \mu \mathrm{m}$ )

At higher concentrations $(0.28 \mathrm{M})$ the effects are even more dramatic (Figure 4). In this case both the presence of proline and alanine show thin square-like particles and glycine shows the most significant impact, producing particles that are too small to be clearly distinguishable in the SEM. 


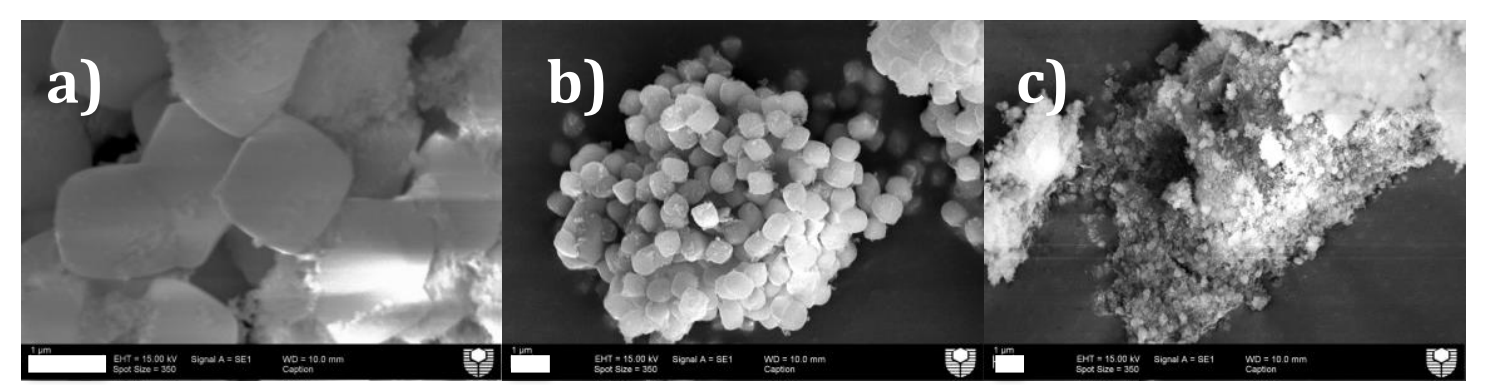

Figure 4. SEM images of jarosite particles formed in the presence of $0.28 \mathrm{M}$ a) alanine, b) proline and, c) glycine (all scale bars $1 \mu \mathrm{m}$ )

At the $\mathrm{pH}$ of 2.9 little impact of the amino acids was observed on the morphology of the resultant particles (See supplementary information SFig. 1).

\section{$3.2 \quad$ Yield}

The impact of amino acids on the yield of solids formed at low $\mathrm{pH}$ correlated with the impact on morphology (Figure 5). Alanine and proline impacted the yield similarly and glycine showed the most significant impact almost completely inhibiting solid formation at 24 hours at a concentration of $0.28 \mathrm{M}$.

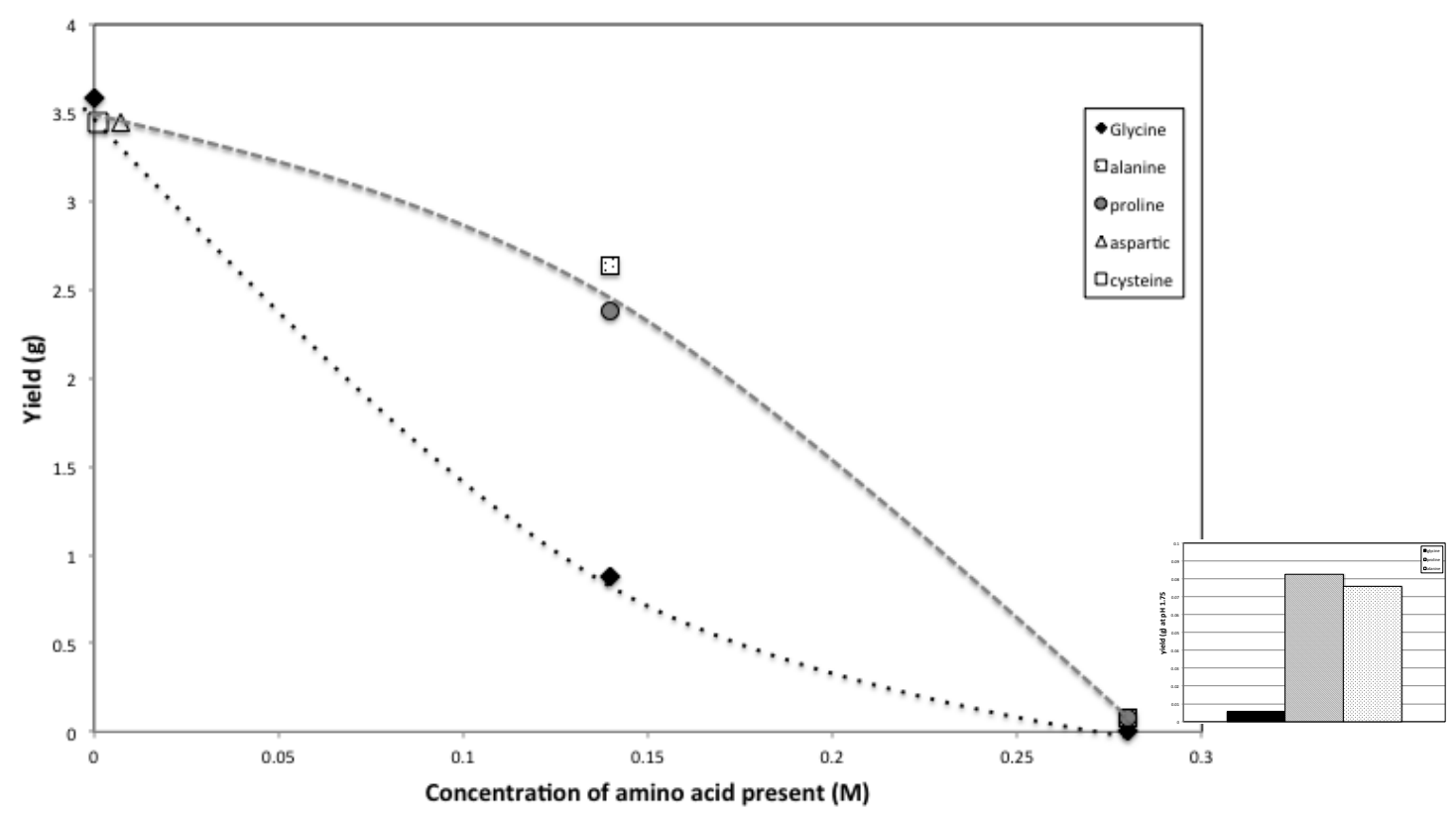

Figure 5. Yield ( $\mathrm{g}$ ) of solids versus concentration of amino acid present for various amino acids (Lines drawn to aid reader only. Bar graph expands the results at $0.28 \mathrm{M}$ amino acid and shows that the 
yield is much lower when glycine is present than when alanine or proline is present)

Once again the amino acids had very little impact on the amount of solids formed at $\mathrm{pH} 2.9$. At this $\mathrm{pH}$ the yield was almost invariant with the amount of amino acid present (see supplementary information, SFig 2).

\section{$3.3 \quad X R D$}

At $\mathrm{pH} 1.75$ the solids formed were always found to be jarosite (Figure 6) regardless of the concentration of amino acid present. At the highest glycine concentration, a very broadened jarosite spectrum was obtained, confirming the small particle size as observed in the SEM images (Figure 4c).

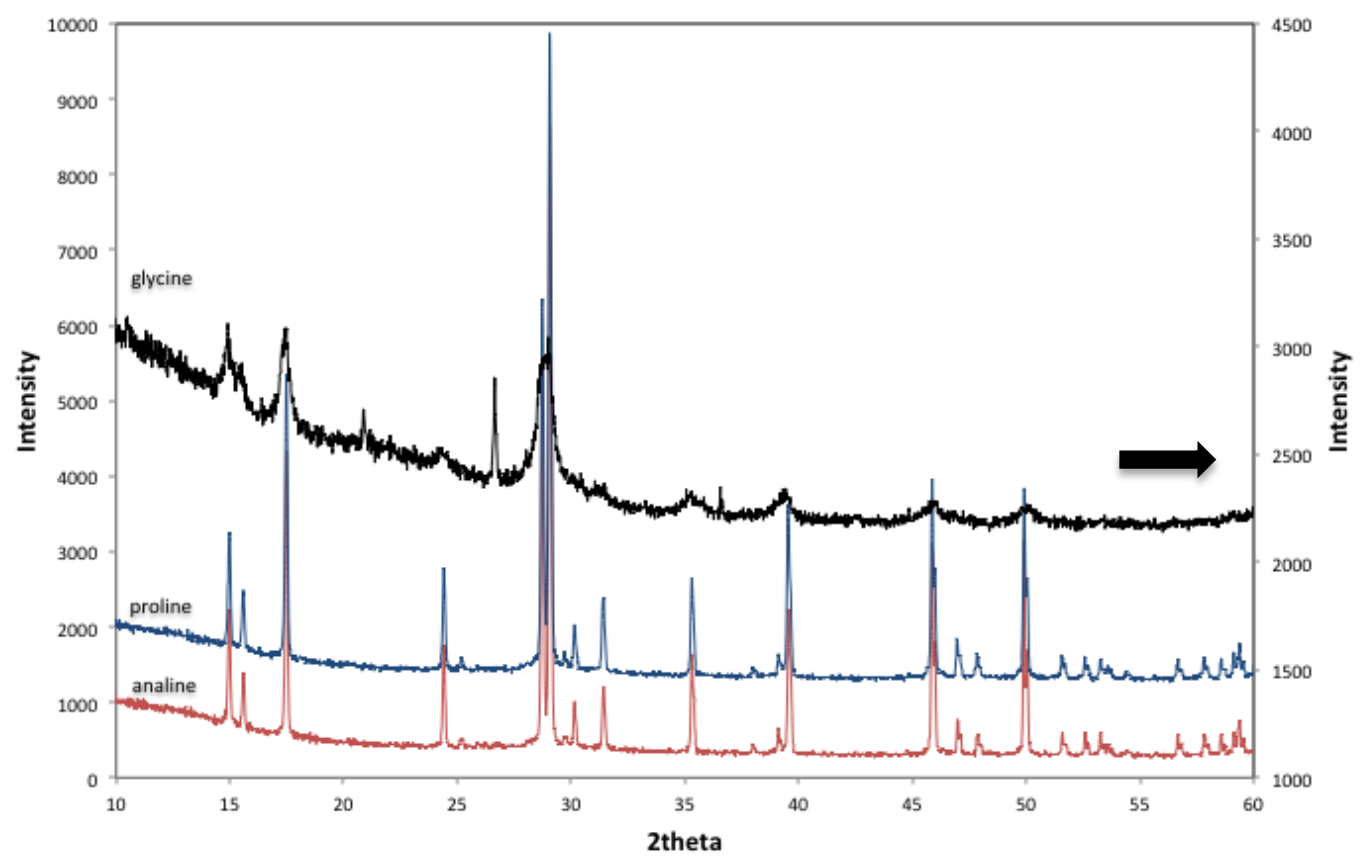

Figure 6. XRD pattern of solids obtained in the presence of $0.28 \mathrm{M}$ alanine, glycine and proline at $\mathrm{pH} 1.75$ and $90^{\circ} \mathrm{C}(24$ hours $)$

Rietveld was conducted on the samples at $0.14 \mathrm{M}$ amino acid (the higher concentration experiments did not produce sufficient solids to be analysed in the same manner). The results can be seen in Table 1 . 
The presence of alanine did not alter the $a$ lattice parameter value beyond the errors of the method with only a small movement in the $c$ value of the jarosite lattice parameter. In the case of glycine, the jarosite XRD pattern could only be fitted reasonably when both a potassium (listed as $\mathrm{K}$ ) and hydronium jarosite (listed as $\mathrm{H}$ ) were assumed to be present. In this case, regardless of whether the potassium or hydronium jarosite is taken into consideration both the $a$ and $c$ parameter are shifted, though the $a$ lattice parameter appears to be most shifted. The presence of proline also shows a significant movement in both lattice parameters. This suggests that the amino acids can incorporate into the structure. A more detailed analysis is warranted whereby the lattice parameters are measured against concentration of amino acid present in order to determine the relationship between $a$ and $c$ axis length with degree of incorporation. This is planned for future work.

Table 1. Rietveld analysis of the jarosite lattice parameters when amino acids are present at $0.14 \mathrm{M}$ and $\mathrm{pH} 1.75$ (24 hours)

\begin{tabular}{lllll}
\hline & $\boldsymbol{a}(\mathbf{\AA})$ & $\boldsymbol{c}(\AA)$ & $\begin{array}{l}\text { Crystallite size } \\
(\mathbf{n m})\end{array}$ & $\begin{array}{l}\text { GOF } \\
\text { (goodness of } \\
\text { fit) }\end{array}$ \\
\hline Control & 7.3114 & 17.0926 & 210 & 1.32 \\
+alanine & 7.3117 & 17.0796 & 190 & 1.38 \\
& $\mathrm{~K}^{\ddagger} 7.3074$ & $\mathrm{~K} 17.1028$ & $\mathrm{~K} 189$ & 1.15 \\
+glycine & $\mathrm{H} 7.324$ & $\mathrm{H} 17.188$ & $\mathrm{H} 10$ & \\
& & & & 1.58
\end{tabular}

* An example of the fitting and difference pattern from such analyses can be found in the supplementary information (SFig. 3).

$\$ \mathrm{~K}$ and $\mathrm{H}$ refer to potassium jarosite and hydronium jarosite respectively. 
At the higher $\mathrm{pH}$ (2.9) it was found that the solids formed consisted of both jarosite and goethite. Rietveld analysis found the composition listed in Table 2. From this data we can see that almost the same amount of jarosite is formed in each case; between 7 to $10 \mathrm{wt} \%$. However, what changes more significantly is the amorphous and goethite content. Table 2 clearly shows that the presence of alanine stabilizes the amorphous content more than the other amino acids and results in both less goethite and slightly less jarosite. Thus, at this higher $\mathrm{pH}$, alanine appears to be the more significant growth modifier in that it stabilizes the metastable amorphous phase more than the other amino acids.

Table 2. Rietveld analysis of the phases formed when amino acids are present at $0.14 \mathrm{M}$ and pH 2.9 (24 hours)

\begin{tabular}{lllll}
\hline & $\begin{array}{l}\text { Goethite } \\
(\mathbf{w t} \%)\end{array}$ & $\begin{array}{l}\text { Amorphous } \\
(\mathbf{w t} \%)\end{array}$ & $\begin{array}{l}\text { Jarosite * } \\
(\mathbf{w t} \%)\end{array}$ & GOF \\
\hline Control & 57.15 & 23.46 & 8.61 & 1.10 \\
+alanine & 53.04 & 30.39 & 6.83 & 1.07 \\
+glycine & 57.50 & 24.36 & 7.24 & 1.07 \\
+proline & 57.48 & 23.32 & 9.60 & 1.12 \\
\hline * Total is less than $100 \%$ due to corundum standard being present also
\end{tabular}

\subsection{Vibrational spectroscopy}

For the most part, the vibrational results confirmed what was already known from the XRD data. However, we did undertake vibrational spectroscopy at the higher $\mathrm{pH}$ (2.9) for shorter times (3 hours). From this data (see Figure 7) it can be seen that the initial products formed in all cases (regardless of concentration of amino acid) is schwertmannite [28]. This is consistent with the amorphous content determined by 
Rietveld and suggests that the alanine is stabilizing the presence of schwertmannite (a known disordered iron sulphate compound [29, 30]). It is also known that goethite can form from schwertmannite and explains the origin of goethite in our samples at $\mathrm{pH} 2.9$ $[30,31]$.

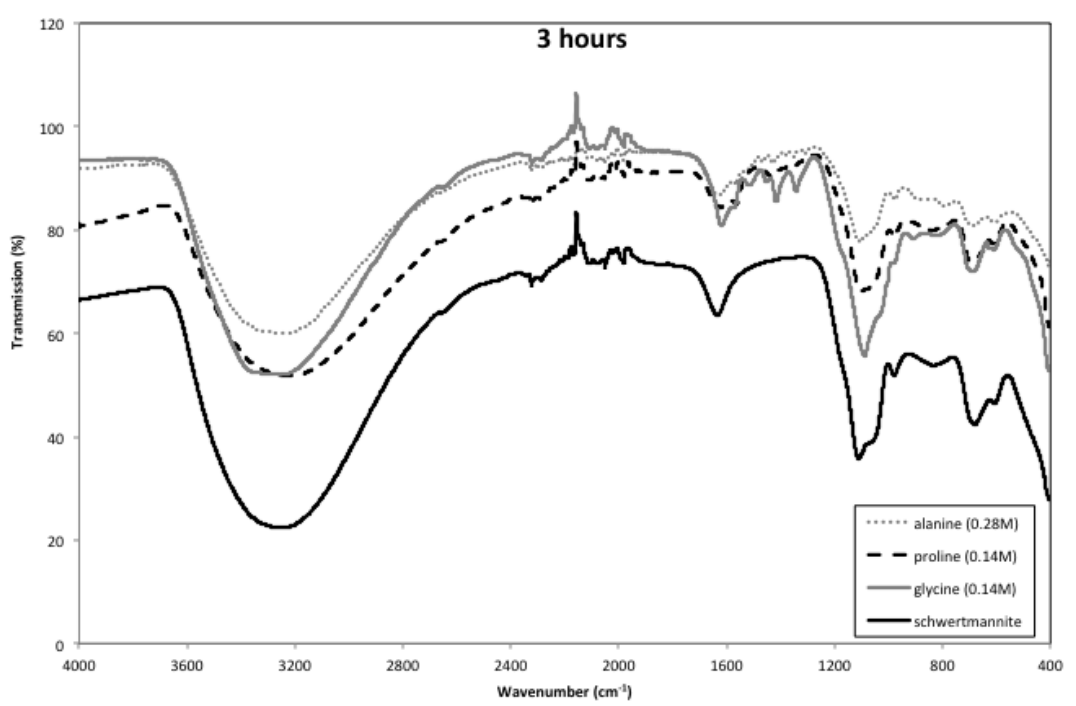

Figure 7. FTIR spectra of solids formed at $\mathrm{pH} 2.9,90^{\circ} \mathrm{C}, 3$ hours in the presence of alanine, proline and glycine at different concentrations (The spectrum of schwertmannite is also shown for comparison)

When all the data is taken together, it suggests that schwertmannite has not completely transformed to goethite by 24 hours and that, therefore, the system at $\mathrm{pH} 2.9$ is in reality a three phase mixed system of goethite, jarosite and schwertmannite.

\subsection{DLS - Induction times}

In order to determine what impacts, if any, these small molecules have on nucleation rates we undertook preliminary experiments to measure the induction times using DLS at pH 2.0 and $0.14 \mathrm{M}$ amino acid. We re-state that since the levels of aspartic acid and cysteine were low, we expect these to have similar nucleation rates as the control and so these were not tested. 


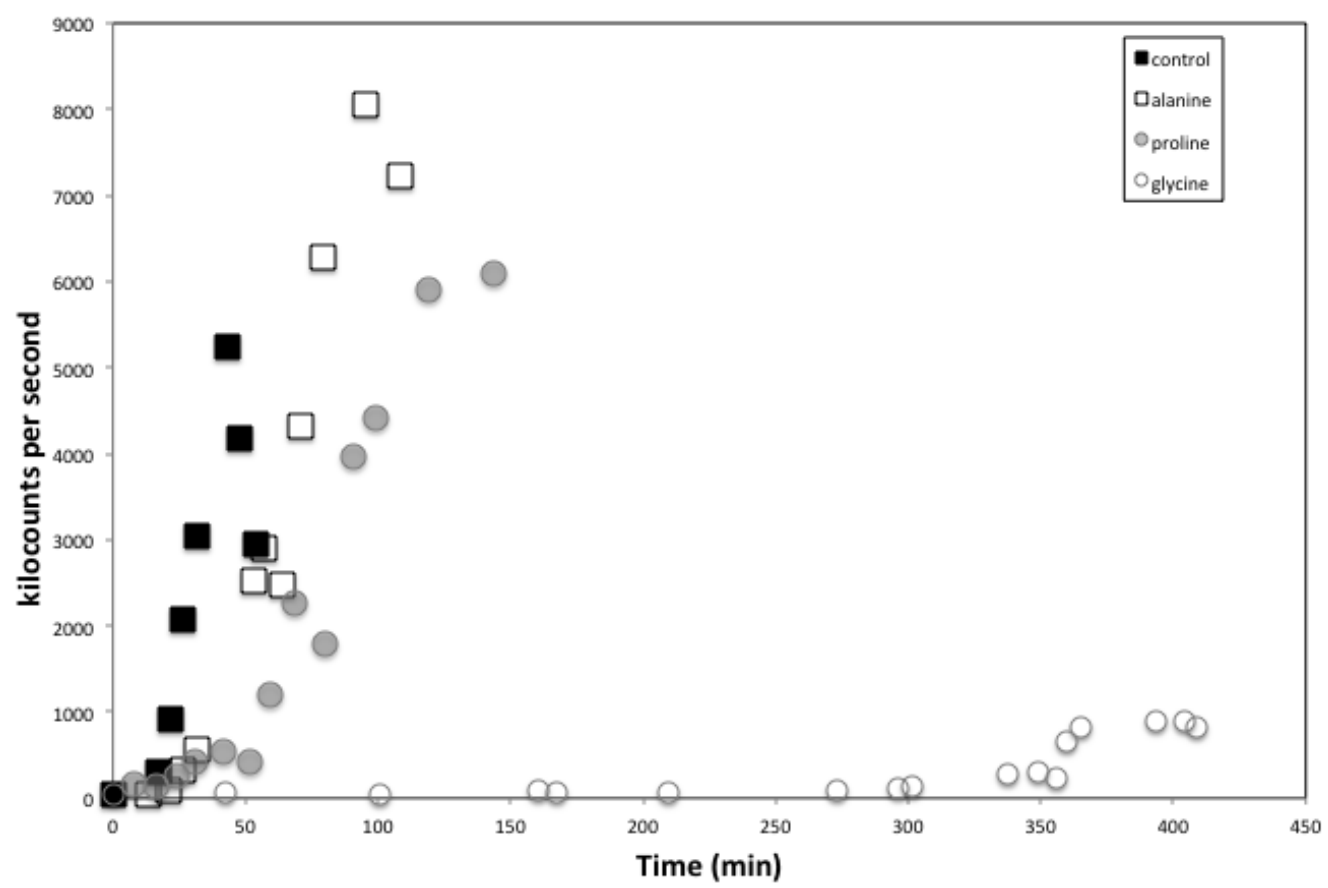

Figure 8. Counts (kilocounts per second) from DLS runs versus time in the absence (control) and presence of $0.14 \mathrm{M}$ alanine, proline and glycine

In the control case, the counts begin to rise at $\sim 25$ minutes. The induction time increases when the amino acids are present but to differing degrees. Only a small increase of $~ 5-10$ minutes in the induction time is observed for the case when alanine and proline is present. When glycine is present, however, the induction time increases dramatically. In the case of $0.14 \mathrm{M}$ glycine the induction time is $\sim 270-300$ minutes. This would suggest that glycine impacts on nucleation dramatically while alanine and proline impact more on the growth processes. This is consistent with the yield and morphology results, which shows a greater impact for glycine than proline or alanine.

The presence of glycine may alter the solubility of jarosite and lead to a lower supersaturation (and therefore a longer induction time), thus we measured the solubility of the control jarosite (formed in the absence of amino acids) in a solution of $\mathrm{KNO}_{3}(6 \mathrm{~g}$ in $200 \mathrm{~mL}$ ) and $\mathrm{H}_{2} \mathrm{SO}_{4}$ at a pH 2.00 with and without $0.28 \mathrm{M}$ glycine at $90{ }^{\circ} \mathrm{C}$ for 24 
hours. The solution was then filtered through a $0.1 \mu \mathrm{m}$ acid resistant membrane (Supor ${ }^{\circledR}$ ) and the iron content measured by ICP-AES. This showed that the amount of iron in solution after 24 hours was $17 \pm 1$ and $23 \pm 1 \mathrm{mg} / \mathrm{L}$ in the absence and presence of glycine respectively. This change in iron solubility is $\sim 35 \%$ and would, therefore, alter the supersaturation. However, the difference in induction time was measured at $0.14 \mathrm{M}$ not $0.28 \mathrm{M}$ glycine, thus the $35 \%$ is an overestimation on the impact on the solubility. Assuming a linear relationship with glycine concentration and solubility, the increase in solubility would then only be $\sim 18 \%$ greater while the induction time is significantly greater (being $1400 \%$ of the control value). Even if we assume an exponential relationship between solubility and nucleation rate, a $18 \%$ increase in solubility would be expected to increase the induction time by a factor of $\sim 3$ not $\sim 14$. Therefore, we conclude that the glycine is impacting the jarosite nucleation rate as well as changing its solubility. This would occur by the glycine adsorbing onto the jarosite critical nuclei and increasing its surface free energy.

\subsection{TGA - thermal behaviour}

Since one of the important properties of jarosites in acid mine drainage situations is their stability, we looked at the thermal stability of the samples formed in the presence of the amino acids (Figure 9). The reproducibility in the mass loss was found to be $\sim 3 \%$ as found for two glycine samples (supplementary information SFig 4.) but even with this error, the mass lost was greater in the presence of glycine than the control. For the other amino acids, the mass loss could be within experimental error. In addition, monitoring of the changes in heat flow (see supplementary information SFig 4.) showed that the solids formed in the presence of alanine followed the control reasonably closely while the solids formed in the presence of glycine and proline 
showed that the exotherm associated with loss of sulphate [32] at $\sim 660^{\circ} \mathrm{C}$ occurred at a lower temperature for these solids $\left(\sim 650^{\circ} \mathrm{C}\right)$.

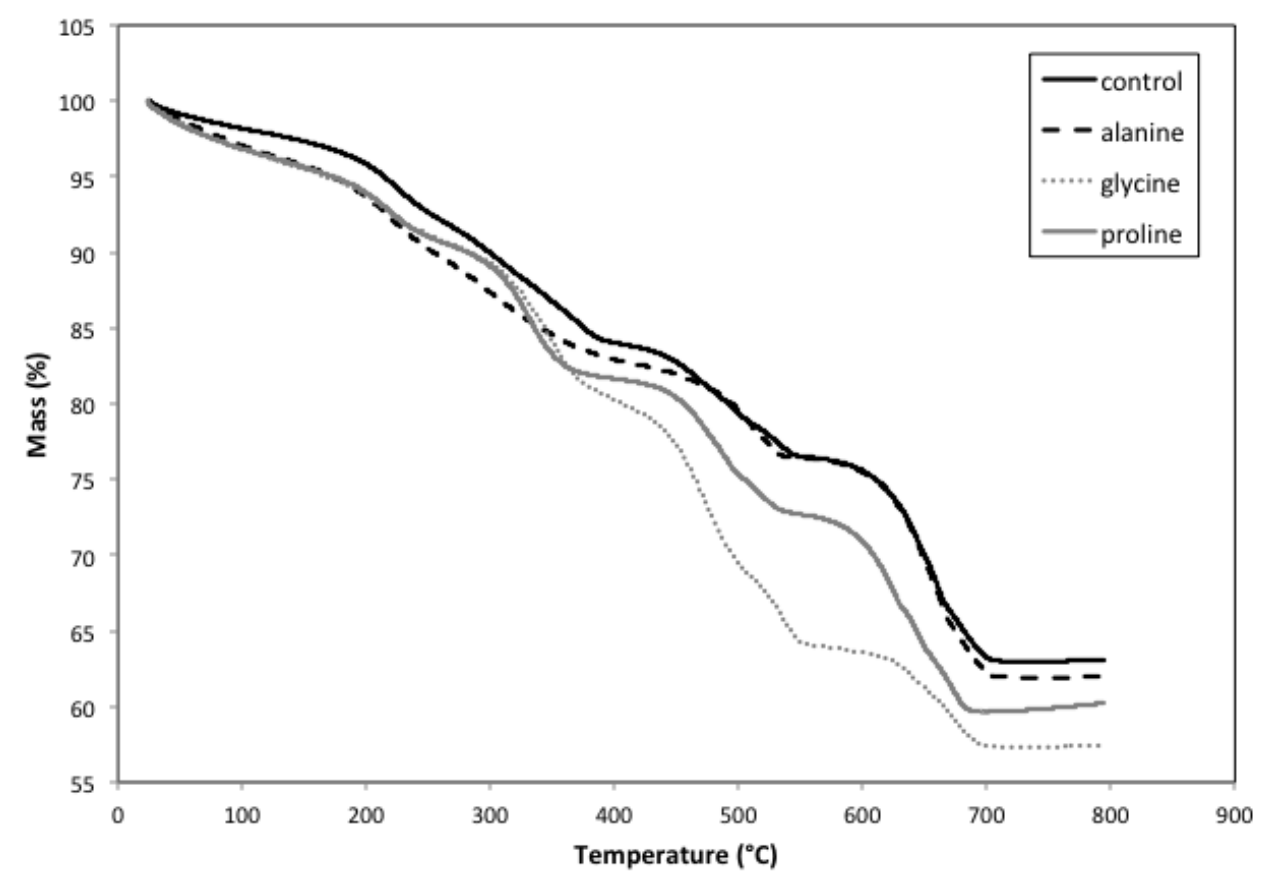

Figure 9. TGA results of mass lost $(\%)$ versus temperature $\left({ }^{\circ} \mathrm{C}\right)$ in the absence and presence of amino acids

Thus, these solids appear to be less thermally stable when the amino acids are present during their formation. This would support the hypothesis of incorporation.

\section{Conclusions and Summary}

It is clear from the results presented here that the $\mathrm{pH}$ is the deciding factor in terms of the phase formed (jarosite versus goethite), despite the fact that organisms can stabilize metastable phases. Despite this, there is a real impact at $\mathrm{pH} 1.75$ on jarosite morphology, yield and crystallinity when amino acids are present and, from the group of amino acids investigated in this work, glycine in particular. Glycine impacts on morphology and yield the most while both glycine and proline are observed to significantly alter the lattice parameters, suggesting incorporation of these molecules 
into the structure as suggested by Kotler [23, 24]. Induction time studies show nucleation is significantly inhibited when glycine is present suggesting that the other amino acids only impact on growth while glycine impacts on both nucleation and growth.

At higher $\mathrm{pH}$ the impact of the amino acids is significantly diminished in terms of impact on morphology or overall yield. In this $\mathrm{pH}$ regime, it is found that alanine is the most potent and its mode of action appears to be to stabilize the amorphous component. From FTIR results this amorphous component is the schwertmannite metastable phase formed initially that over time transforms to goethite. While it has previously been observed that goethite can form from schwertmannite, it is not clear that this is the metastable phase prior to jarosite formation. This aspect needs further investigation.

Finally, while future work will be focused on obtaining sufficient solids to conduct solubility and dissolution experiments for the jarosites formed, there is still a lot of work to be done to determine the impact of other amino acids and combinations thereof before we progress to understanding the impacts of live organisms. We are working on this aspect.

\section{Acknowledgements}

We would like to thank Peter Chapman for the TGA analysis and acknowledge the Curtin Centre for Materials Research, Curtin University for use of the SEM and XRD facilities. We would also like to thank Prof. Kate Wright for valuable discussions and comments. 


\section{References}

[1] I. Bibi, B. Singh, E. Silvester (2011), Geochimica et Cosmochimica Acta, 75, 6429-6438.

[2] S. Das and M. J. Hendry (2011), Chemical Geology, 290, 101-108.

[3] D. T. Long, N. E. Fegan, J. D. McKee, W. B. Lyons, M. E. Hines, P. G. Macumber (1992), Chemical Geology, 96(1-2), 183-202.

[4] J. E. Dutrizac and J. L. Jambor, (2000), Rev. Min. Geochem., 40, 405-453.

[5] M.J. Leahy, M. P. Schwarz (2009), Hydrometallurgy, 98, 181-191.

[6] K. Sasaki, K. Takatsugi, T. Hirajima (2011), Hydrometallurgy, 109, 153-160.

[7] G. Klingelhöfer, R. V. Morris, B. Bernhardt, C. Schröder, D. S. Rodinov, P. A. de Souza Jnr., A. Yen, R. Gellert, E. N. Evalanov, D. W. Ming, F. Renz, T. Wdowiak, S. W. Squyres, R. E. Arvidson (2004), Science, 306, 1740-1745.

[8] M. Egal, C. Casiot, G. Morin, M. Parmentier, O. Bruneel, S. Lebrun, F. Elbaz-Poulichet (2009), Chemical Geology, 265, 432-441.

[9] S. Hedrich, H. Lünsdorf, R. Kleeberg, G. Heide, J. Seifert, M. Schlömann (2011), Environmental Science \& Technology, 45, 7685-7692.;

[10] Y. Liao, L. Zhou, J. Liang, H. Xiong (2009), Materials Science \& Engineering C-Biomimetic and Supramolecular Systems, 29, 211-215.

[11] M.-O. Figueiredo, T. Pereira da Silva (2011), Int. J. Environ. Res. Public Health, 8, 1575-1582.

[12] K. Sasaki (1997), Canadian Mineralogist, 35, 999-1008.

[13] T. Becker, N. Gorham, D. W. Shiers, H. R. Watling (2011), Process Biochemistry, 46, 966-976.

[14] J. P. Gramp, H. Wang, J. M. Bigham, F. S. Jones, O. H. Tuovinen (2009), Geomicrobiology Journal, 26(4), 275-280.

[15] L. Jin-yan, T. Xiu-xiang, C. Pei (2009), Procedia Earth and Planetary Science, 1, 706-712.

[16] A. M. L. Smith, W. E. Dubbin, K. Wright, K. A. Hudson-Edwards (2006), Chemical Geology, 229, 344-361.

[17] A. M. L. Smith, K. A. Hudson-Edwards, W. E. Dubbin, K. Wright (2006), Geochimica et Cosmochimica Acta, 70, 608-621.

[18] C. M. Smeaton, B. J. Freyer, C. G. Weisener (2009), Environ. Sci. Technol., 43, 8086-8091.

[19] K. Sasaki, H. Konno (2000), Canadian Mineralogist, 38, 45-56. 
[20] R. Amils, V. de la Fuente, N. Rodríguez, J. Zuluaga, N. Menéndez, J. Tornero, (2007) Plant Physiology and Biochemistry, 45, 335-340.

[21] K. Tazaki, T. Mori, T. Nonaka (1992), Canadian Mineralogist, 30, 431-444.

[22] G. M. Mudd (2004), Proc. 11th International Conference on Tailings \& Mine Waste '04, Taylor \& Francis Group, ISBN 041535939 2, pp 359-369.

[23] J. M. Kotler, N. W. Hinman, C. D. Richardson, A. G. Conly, J. R. Scott, (2009), Planetary and Space Science, 57, 1381-1388.

[24] J. M. Kotler, N. W. Hinman, B. Yan, D. L. Stoner, J. R. Scott, (2008), Astrobiology, 8(2), 253 266.

[25] J. E. Dutrizac, O. Dinardo, S. Kaiman (1980), Hydrometallurgy, 5, 305-324.

[26] J. L. Bishop (2005), American Mineralogist, 90(7), 1100-1107.

[27] J. W. Mullin (1961), Nucleation. In Crystallization, 3rd ed.; Butterworth-Heinemann: Oxford, pp 172-201.

[28] J.-F. Boily, P. L. Gassman, T. Peretyazhko, J. Szanyi, J. M. Zachara (2010), Environ. Sci. Technol., 44, 1185-1190.

[29] M. Loan, J. M. Cowley, R. Hart, G. M. Parkinson (2004), American Mineralogist, 89(11-12), 1735-1742.

[30] J. G. Hockridge, F. Jones, M. Loan, W. R. Richmond (2009), J. Cryst. Growth, 311, 3876-3882.

[31] P. Acero, C. Aroya, C. Torrentò, J. M. Nieto (2006), Geochimica et Cosmochimica Acta, 70(16), 4130-4139.

[32] G. A. Desborough, K. S. Smith H. A. Lowers, G. A. Swayze, J. M. Hammarstrom, S. F. Diehl, R. W. Leinz, R. L. Driscoll (2010), Geochimica et Cosmochimica Acta, 74, 1041-1056. 